https://helda.helsinki.fi

\title{
Minimal volume ventilation during robotically assisted mitral valve surgery
}

Kesävuori, Risto

2019-11

Kesävuori , R , Vento , A , Lundbom , N , Schramko , A , Jokinen , J J \& Raivio , P 2019 , '

Minimal volume ventilation during robotically assisted mitral valve surgery ' , Perfusion, vol.

34 , no. 8 , pp. 705-713 . https://doi.org/10.1177/0267659119847917

http://hdl.handle.net/10138/322091

https://doi.org/10.1177/0267659119847917

publishedVersion

Downloaded from Helda, University of Helsinki institutional repository.

This is an electronic reprint of the original article.

This reprint may differ from the original in pagination and typographic detail.

Please cite the original version. 


\section{Minimal volume ventilation during \\ robotically assisted mitral valve surgery}

\author{
Risto Kesävuori, ',2 (D) Antti Vento,' Nina Lundbom,2 \\ Alexey Schramko, ${ }^{3}$ Janne J Jokinen ${ }^{4}$ and Peter Raivio'
}

\begin{abstract}
Perfusion
2019, Vol. 34(8) 705-713

(c) The Author(s) 2019

Article reuse guidelines: sagepub.com/journals-permissions DOI: $10.1177 / 0267659 \mid 19847917$ journals.sagepub.com/home/prf
\end{abstract}

๑SAGE

\begin{abstract}
Introduction: A minimal volume ventilation method for robotically assisted mitral valve surgery is described in this study. In an attempt to reduce postoperative pulmonary dysfunction, 40 of 174 patients undergoing robotically assisted mitral valve surgery were ventilated with a small tidal volume during cardiopulmonary bypass.

Methods: After propensity score matching, 31 patients with minimal volume ventilation were compared with 54 patients with no ventilation. Total ventilation time, $\mathrm{PaO}_{2} / \mathrm{FiO}_{2}$ ratio, arterial lactate concentration, and the rate of unilateral pulmonary edema in the matched minimal ventilation and standard treatment groups were evaluated.

Results: Patients in the minimal ventilation group had shorter ventilation times, 12.0 (interquartile range: 9.9-15.0) versus 14.0 (interquartile range: $12.0-16.3)$ hours $(p=0.036)$, and lower postoperative arterial lactate levels, 0.99 (interquartile range: $0.8 \mathrm{I}-\mathrm{I} .39$ ) versus $\mathrm{I} .28$ (interquartile range: $0.99-\mathrm{I} .86) \mathrm{mmol} / \mathrm{L}(\mathrm{p}=0.0 \mathrm{I})$, in comparison to patients in the standard treatment group. There was no difference in postoperative $\mathrm{PaO}_{2} / \mathrm{FiO}_{2}$ ratio levels or in the rate of unilateral pulmonary edema between the groups.

Conclusion: Minimal ventilation appeared beneficial in terms of total ventilation time and blood lactatemia, while there was no improvement in arterial blood gas measurements or in the rate of unilateral pulmonary edema. The lower postoperative arterial lactate levels may suggest improved lung perfusion among patients in the minimal volume ventilation group. The differences in the ventilation times were in fact small, and further studies are required to confirm the possible advantages of the minimal volume ventilation method in robotically assisted cardiac surgery.
\end{abstract}

\title{
Keywords
}

anesthesia; minimally invasive surgery; mitral valve; perioperative care; pulmonary function; robotics; ventilation

\section{Introduction}

Minimally invasive and robotically assisted methods have been increasingly utilized in cardiac surgery. Robotically assisted methods have been most commonly adopted in mitral valve operations, while robotic coronary artery bypass grafting, robotic atrial septal defect closures, and robotic myxoma excisions have also been performed. In many series, the safety and outcomes of robotically assisted cardiac operations have been comparable to the results of conventional sternotomy operations. ${ }^{1-8}$

In robotically assisted operations, cardiopulmonary bypass $(\mathrm{CPB})$ is accomplished via the femoral artery and vein, and aortic occlusion is performed either with an endoaortic balloon or directly with the Chitwood clamp transthoracically. In robotically assisted mitral valve surgery, exposure is obtained from a right minithoracotomy. The right lung is collapsed to gain surgical access to the heart, requiring simultaneous ventilation of the left lung. One-lung ventilation (OLV) is accomplished using either a double-lumen endotracheal tube or a bronchial blocker.

Minimally invasive cardiac surgery with OLV has been associated with postoperative pulmonary dysfunction

\footnotetext{
'Department of Cardiac Surgery, Heart and Lung Center, Helsinki University Hospital, Helsinki, Finland

${ }^{2}$ Department of Radiology, HUS Medical Imaging Center, Helsinki University Hospital, Helsinki, Finland

3Department of Anaesthesiology, Intensive Care and Pain Medicine, Helsinki University Hospital, Helsinki, Finland

${ }^{4}$ Department of Surgery, Päijät-Häme Central Hospital, Lahti, Finland
}

\section{Corresponding author:}

Risto Kesävuori, Department of Cardiac Surgery, Heart and Lung Center, Helsinki University Hospital, Haartmaninkatu 4, Helsinki 00029, Finland.

Email: risto.kesavuori@helsinki.fi 
and postoperative unilateral pulmonary edema (UPE) of the collapsed lung with high morbidity and mortality.9-15 The patophysiology of UPE is unknown, but previous studies have hypothesized that ischemia-reperfusion might contribute to the development of UPE.9,10,14 Even though blood flow to the collapsed lung is reduced physiologically by hypoxic pulmonary vasoconstriction to minimize transpulmonary shunting, part of the blood flow is shunted via the collapsed lung predisposing to hypoxemia. Inferior $\mathrm{PaO}_{2} / \mathrm{FiO}_{2}$ ratios after $\mathrm{CPB}$ have been reported among patients operated using OLV in comparison to double-lung ventilation. ${ }^{16}$

Increased CPB duration has been associated with elevated postoperative lactate levels ${ }^{17-20}$ and increased morbidity and mortality among patients undergoing cardiac surgery from sternotomy. $17,18,20$ Notably, the lungs have been shown to be a significant source of lactate production during cardiac surgery. ${ }^{19,21}$

In cardiac surgery with the sternotomy approach, the effects of continuous positive airway pressure (CPAP) and mechanical ventilation during $\mathrm{CPB}$ on postoperative oxygenation and pulmonary dysfunction have been previously evaluated with varying results and also recent meta-analyses have been published.22,23 In the metaanalyses, CPAP during CPB has improved postoperative oxygenation without any effect on the clinical outcomes. In thoracic surgery with OLV, improved postoperative oxygenation, reduced pulmonary shunting, and reduced local inflammatory response in the affected lung have been reported after CPAP or high-frequency jet ventilation (HFJV) during CPB. ${ }^{24-28}$ Also, adding positive endexpiratory pressure (PEEP) to the ventilated lung may enhance oxygenation during OLV. ${ }^{29,30}$

In robotically assisted mitral valve surgery, the use of CPAP or PEEP during CPB is not feasible due to the resulting restricted visibility in the surgical field. Therefore, ventilation of the lungs with a small tidal volume during $\mathrm{CPB}$ without PEEP (minimal volume ventilation (MVV)) was adopted in our institution in an attempt to reduce postoperative hypoxemia and UPE. Both lungs of 40 of 174 patients undergoing robotically assisted mitral valve surgery were ventilated with a small tidal volume during CPB. To assess the potential benefits of MVV, total ventilation time, postoperative $\mathrm{PaO}_{2} / \mathrm{FiO}_{2}$ ratio, arterial lactate concentration, and the rate of UPE were evaluated. Propensity score matching (PSM) was utilized to compare MVV patients and patients who were not ventilated during CPB (standard treatment group).

\section{Methods}

\section{Patients and data collection}

A total of 174 consecutive patients who underwent robotic mitral valve surgery at our institution between May 2011 and March 2017 were reviewed for this study.
Of these, 40 patients were ventilated using MVV. In this study, the effect of MVV on postoperative pulmonary function is evaluated. Therefore, in order to reduce the presumable confounding effect of early reoperations and sternotomy conversions on the analysis, patients who underwent conversion to open sternotomy or thoracotomy or were reoperated during the first postoperative 24 hours due to surgical complications were excluded from the study (7/40 (17.5\%) and 21/134 (15.4\%) patients with MVV and standard treatment, respectively $(\mathrm{p}=0.808))$. The preoperative characteristics of the 146 patients who met the inclusion criteria are presented in Table 1, including 33 patients who were ventilated using the minimal ventilation method and 113 patients who were treated in the standard fashion and disconnected from the ventilator during CPB.

To reduce selection bias, PSM in a 2:1 ratio was employed using 11 pre-selected variables that included risk factors for UPE and for prolonged ventilation reported in recent studies. ${ }^{10,13}$ PSM resulted in two well-matched study groups of 31 and 54 patients in the minimal ventilation and the standard ventilation groups, respectively. The patient flow diagram is presented in Figure 1.

Postoperative $\mathrm{PaO}_{2} / \mathrm{FiO}_{2}$ ratios and arterial lactate levels were assessed to evaluate postoperative pulmonary function. The chest radiographs from the first postoperative day were evaluated by a radiologist (N.L.). UPE was defined as unilateral pulmonary edema of the right lung, where at least $25 \%$ of the right hemithorax was opacified and showed either interstitial thickening indicating interstitial edema or air bronchograms and consolidation indicating alveolar edema.

This study was approved by the local institutional board and the local ethics committee.

\section{Operative technique and perioperative care}

All operations were performed using the da Vinci ${ }^{\circledR} \mathrm{Si}$ Surgical system (Intuitive Surgical, Sunnyvale, CA, USA). The service port and the ports for the endoscope and the robotic arms were placed in the right intercostal spaces. The right femoral artery was cannulated with a 21- or 23-Fr arterial cannula (EndoReturn ${ }^{\mathrm{TM}}$, Edwards Lifesciences, Irvine, CA, USA), and bicaval venous cannulation was established via right femoral and jugular veins. Bipolar intracardiac pacemaker was administered via the right subclavian vein, and a Swan-Ganz catheter was applied when necessary. In the first operations, antegrade cold crystalloid cardioplegia was used alone. In the later operations, retrograde cardioplegia was also delivered using a coronary sinus catheter (ProPlege ${ }^{\mathrm{TM}}$, Edwards Lifesciences), cardioplegia solution was changed to intermittent cold blood cardioplegia, and perfusion temperature was lowered to $32^{\circ} \mathrm{C}$ to ensure adequate myocardial protection. Aortic occlusion was performed primarily with an endoaortic balloon (EndoClamp ${ }^{\mathrm{TM}}$ or IntraClude ${ }^{\mathrm{TM}}$, Edwards Lifesciences), but the Chitwood 
Table I. Demographic data prior to propensity score matching.

\begin{tabular}{|c|c|c|c|c|}
\hline Demographic data & $\begin{array}{l}\text { Minimal ventilation } \\
(n=33)\end{array}$ & $\begin{array}{l}\text { Standard treatment } \\
(\mathrm{n}=|| 13)\end{array}$ & $P$ value & $\begin{array}{l}\text { Standardized } \\
\text { difference }\end{array}$ \\
\hline Male $^{a}$ & $26(78.8)$ & $90(79.6)$ & 1.000 & 0.02 \\
\hline Age $^{a}$ (years) & $57.3(13.6)$ & $59.5(10.6)$ & 0.338 & 0.18 \\
\hline $\mathrm{BSA}^{\mathrm{a}}\left(\mathrm{m}^{2}\right)$ & $1.99(0.26)$ & $1.98(0.20)$ & 0.881 & 0.04 \\
\hline $\mathrm{GFR}^{\mathrm{a}}(\mathrm{mL} / \mathrm{min})$ & $96(35)$ & $94(28)$ & 0.676 & 0.06 \\
\hline Pulmonary hypertension ${ }^{\mathrm{a}}$ & & & 0.110 & \\
\hline Normal & $20(60.6)$ & $46(40.7)$ & & 0.41 \\
\hline Moderate & $9(27.3)$ & $52(46.0)$ & & 0.40 \\
\hline Severe & $4(12.1)$ & $15(13.3)$ & & 0.03 \\
\hline Atrial fibrillation $^{a}$ & $14(42.4)$ & $32(28.3)$ & 0.140 & 0.30 \\
\hline Ejection fraction ${ }^{a}$ & & & 1.000 & \\
\hline$>50 \%$ & $31(93.9)$ & $105(92.9)$ & & 0.04 \\
\hline$\leqslant 50 \%$ & $2(6.1)$ & $8(7.1)$ & & 0.04 \\
\hline $\mathrm{NYHA}^{\mathrm{a}}$ & & & 0.124 & \\
\hline I & $7(2 \mid .2)$ & $15(13.3)$ & & 0.21 \\
\hline II & $17(5 \mid .5)$ & $50(44.2)$ & & 0.15 \\
\hline III & $7(2 \mid .2)$ & $46(40.7)$ & & 0.43 \\
\hline IV & $2(6.1)$ & $2(1.8)$ & & 0.22 \\
\hline Diabetes $^{\mathrm{a}}$ & & & 0.261 & \\
\hline No diabetes & $30(90.9)$ & I I $0(97.3)$ & & 0.21 \\
\hline Non-insulin dependent & I (3.0) & I (0.9) & & 0.11 \\
\hline Insulin dependent & $2(6.1)$ & $2(1.8)$ & & 0.17 \\
\hline Smoking ${ }^{\mathrm{a}}$ & & & 0.618 & \\
\hline No smoking & $27(81.8)$ & $84(74.3)$ & & 0.28 \\
\hline Ex-smoker & $4(12.1)$ & $22(19.5)$ & & 0.20 \\
\hline Current smoker & $2(6.1)$ & $7(6.2)$ & & 0.01 \\
\hline COPD & 0 & 0 & 1.000 & \\
\hline Asthma & I (3.0) & $4(3.5)$ & 1.000 & \\
\hline Hypertension & II (33.3) & $36(31.9)$ & 1.000 & \\
\hline Stroke & I (3.0) & I (0.9) & 1.000 & \\
\hline TIA & I (3.0) & 0 & 1.000 & \\
\hline EuroSCORE I & $2.08(1.51-3.13)$ & $1.96(I .5 I-2.7 I)$ & 0.821 & \\
\hline Degenerative mitral valve disease & $33(100)$ & $113(100)$ & 1.000 & \\
\hline Mitral valve leaflet pathology & & & 0.417 & \\
\hline Isolated posterior leaflet & $24(72.7)$ & $92(82.1)$ & & \\
\hline Isolated anterior leaflet & $4(12.1)$ & $11(9.8)$ & & \\
\hline Bileaflet & $5(15.2)$ & $9(8.0)$ & & \\
\hline
\end{tabular}

BSA: body surface area; GFR: glomerular filtration rate; NYHA: New York Heart Association; COPD: chronic obstructive pulmonary disease; TIA: transient ischemic attack; EuroSCORE: European System for Cardiac Operative Risk Evaluation.

Data shown as number of patients (\%) or mean \pm SD (range) or median (interquartile range).

aVariables included in propensity score matching.

clamp was used in some operations. The endoaortic balloon was placed under echocardiographic guidance during rapid ventricular pacing. If ventricular pacing was not functioning, an intravenous adenosine bolus was administered.

\section{Anesthesia}

Anesthesia was induced with propofol or etomidate, fentanyl, and rocurone and maintained with sevoflurane and opioid (fentanyl, alfentanil, or sufentanil). Inotropic or vasoconstrictive medications were administered when needed. Intravenous cefuroxime and vancomycin were routinely administered at induction. Patients were intubated using a double-lumen endotracheal tube to allow OLV. The double-lumen endotracheal tube was exchanged for a standard endotracheal tube postoperatively in the operating room.

\section{Ventilation and extubation}

When the operation started, OLV of the left lung was instituted and the right lung was allowed to collapse, and all patients were disconnected from the ventilator when $\mathrm{CPB}$ started. In the minimal ventilation group, 


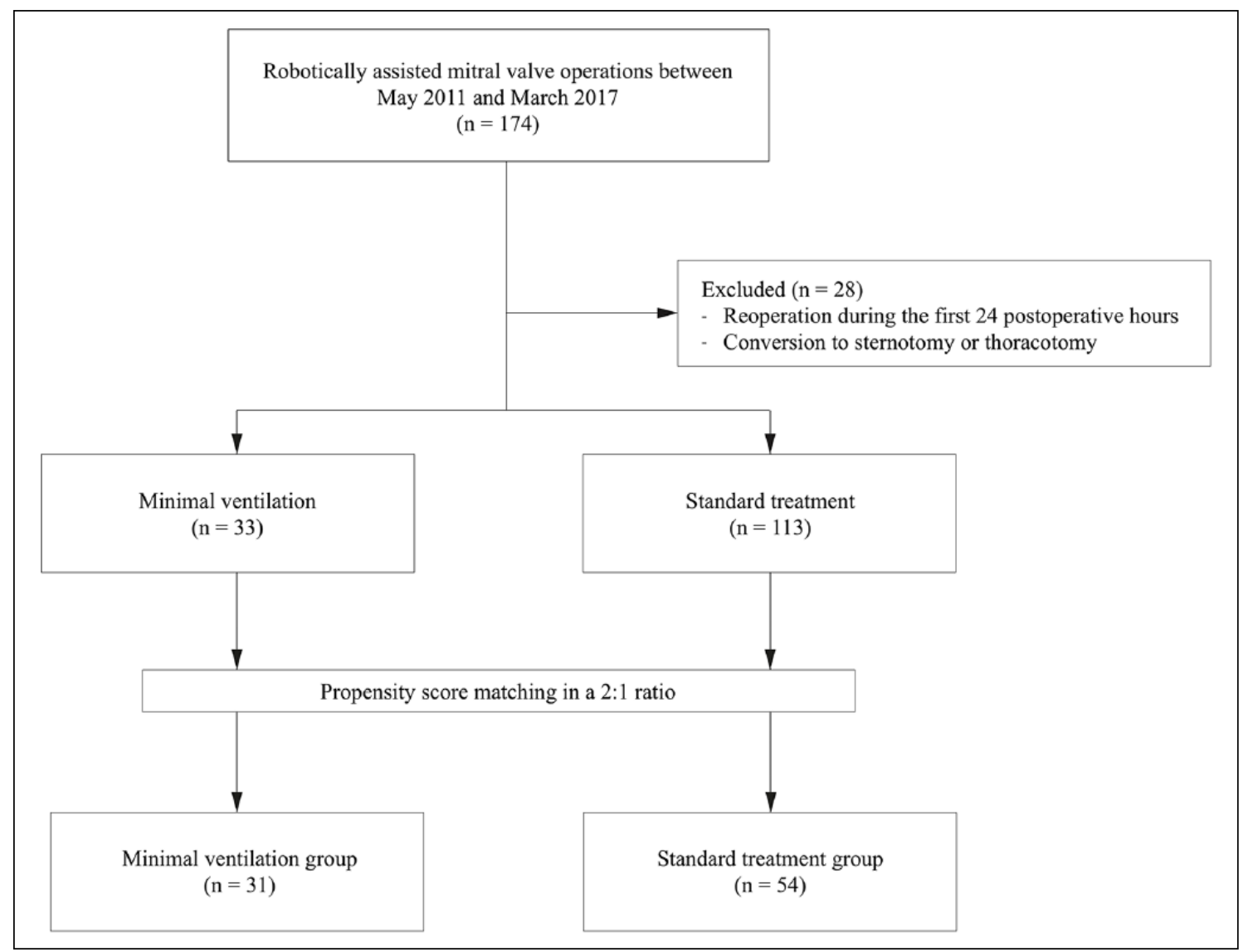

Figure I. Patient flow diagram.

minimal ventilation of both lungs (tidal volume: $50-80 \mathrm{~mL}$, respiratory rate: $6-8 / \mathrm{min}, \mathrm{FiO}_{2}: 25-35 \%$, PEEP: 0) was started after aortic occlusion and continued throughout CPB. In the standard treatment group, patients were kept disconnected from the ventilator during CPB.

The extubation criteria are listed in Table 2. These criteria are used for both conventional sternotomy operations and for robotically assisted or minimally invasive thoracoscopic operations. These criteria have been unchanged during our robotic program between the years 2011 and 2017.

\section{Statistical analysis and PSM}

IBM SPSS ${ }^{\circledR}$ version 24.0 (IBM Corp., Armonk, NY, USA) was used for statistical analysis and data collection. Kolmogorov-Smirnov test was performed to test the normality of the continuous variables. Nominal values are reported as counts and percentages, and continuous variables are reported as median and interquartile range (IQR) or as mean and standard deviation. The Mann-Whitney U-test or the independent samples T-test was used to test the differences of the continuous variables between the study groups, and Chi-square or Fisher's exact test was
Table 2. Extubation criteria after robotically assisted mitral valve surgery.

Patient responds adequately to verbal stimuli

Stable hemodynamics

Normothermia

No active bleeding

$\mathrm{FiO}_{2}<40 \%$

$\mathrm{EtCO}_{2}$ between 4.5 and $5.5 \mathrm{kPa}$

$\mathrm{PaO}_{2}>10 \mathrm{kPa}$

$\mathrm{PaCO}_{2}$ between 4.5 and $5.5 \mathrm{kPa}$ or at the preoperative level $\mathrm{pH}$ between 7.35 and 7.42

Respiratory rate of mechanical ventilation $<2 /$ min

Patient's own respiratory rate $<20 / \mathrm{min}$

PEEP $<6 \mathrm{cmH}_{2} \mathrm{O}$

$\mathrm{FiO}_{2}$ : fraction of inspired oxygen; $\mathrm{EtCO}_{2}$ : end-tidal carbon dioxide; $\mathrm{PaO}_{2}$ : arterial partial pressure of oxygen; $\mathrm{PaCO}_{2}$ : arterial partial pressure of carbon dioxide; PEEP: positive end-expiratory pressure.

used to test the differences of the categorical variables. The $\alpha$-level was set at 0.05 for statistical significance.

PSM was employed to reduce selection bias and to balance the two study groups with respect to covariates that might affect the postoperative clinical course and outcomes of the ventilation-related parameters. The covariates that were included in the propensity score 
Table 3. Operative data prior to propensity score matching.

\begin{tabular}{|c|c|c|c|c|}
\hline Operative data & $\begin{array}{l}\text { Minimal ventilation } \\
(n=33)\end{array}$ & $\begin{array}{l}\text { Standard treatment } \\
(\mathrm{n}=1 \mid 3)\end{array}$ & $P$ value & $\begin{array}{l}\text { Standardized } \\
\text { difference }\end{array}$ \\
\hline CPB time ${ }^{a}(\min )$ & $148(127-166)$ & $154(135-177)$ & 0.205 & 0.25 \\
\hline Cross-clamp time (min) & $102(87-124)$ & $105(90-125)$ & 0.470 & \\
\hline Console time (min) & $125(107-145)$ & $130(\mid 12-157)$ & 0.319 & \\
\hline Operation length (min) & $247(22$ I-270) & $248(225-278)$ & 0.748 & \\
\hline \multicolumn{5}{|l|}{ Concomitant surgery } \\
\hline TVP & I (3.0) & $4(3.5)$ & 1.000 & \\
\hline AF ablation & $10(30.3)$ & $23(20.4)$ & 0.243 & \\
\hline Myxoma resection & I (3.0) & 0 & 1.000 & \\
\hline Mitral valve repair & $33(100)$ & $112(99.1)$ & 1.000 & \\
\hline Isolated neochord implantation & $18(54.5)$ & $49(43.8)$ & 0.323 & \\
\hline Isolated leaflet resection & $7(2 \mid .2)$ & $43(38.4)$ & 0.095 & \\
\hline Neochord and resection & $5(15.2)$ & $6(5.4)$ & 0.126 & \\
\hline Commissuroplasty or cleft closure & $3(9.1)$ & $10(8.9)$ & 1.000 & \\
\hline Isolated annuloplasty & 0 & $2(1.8)$ & 1.000 & \\
\hline
\end{tabular}

CPB: cardiopulmonary bypass; TVP: tricuspid valve repair; AF: atrial fibrillation.

Data shown as number of patients (\%) or mean \pm SD (range) or median (interquartile range).

a $V$ ariables included in propensity score matching.

analysis are presented in Tables 1 and 3 and included patient age, sex, body surface area (BSA), smoking status, glomerular filtration rate (GFR), pulmonary artery systolic pressure, atrial fibrillation (AF), New York Heart Association (NYHA) class, ejection fraction (EF), diabetes, and $\mathrm{CPB}$ time. These covariates were preselected and included potential risk factors for UPE and prolonged ventilation. Altogether, 146 patients were included in the PSM, with 33 patients who were ventilated using MVV and 113 patients who were ventilated using the standard method during $\mathrm{CPB}$. The inclusion of CPB time in the PSM aimed to match the right lung collapse time between the groups. In addition, matching of $\mathrm{CPB}$ time between the groups was considered to reduce the confounding effect of the learning curve of a robotic cardiac surgery program, which is associated with longer operative times during the first operations. ${ }^{31}$

PSM was performed in a 2:1 ratio to ensure an adequate number of study patients. Matching was conducted without replacement using the nearest neighbor algorithm with a 0.3 caliper resulting in two wellmatched study groups of 31 and 54 patients in the minimal and standard ventilation groups, respectively. PSM was also tested using the greedy algorithm in a 2:1 ratio. The greedy algorithm resulted in a larger number of matched patients (33 and 66 patients in the minimal ventilation and standard treatment groups, respectively), but the standardized differences of the PSM covariates between the study groups were not within acceptable limits. We therefore considered caliper matching superior to the greedy matching algorithm, resulting in two study groups of 31 and 54 patients in the MVV and standard treatment groups, respectively. The resulting standardized differences of the covariates that were included in the PSM are presented in Tables 4 and 5 . A standardized difference of $\leqslant 0.1$ was considered a good match. In our data, the only variables with a standardized difference $>0.1$ were preoperative NYHA IV class and preoperative diabetes status. NYHA IV heart failure symptoms were more common in the minimal ventilation group as there were $2(6.5 \%)$ versus 2 (3.7\%) patients in the minimal ventilation and the standard treatment groups, respectively, with a standardized difference of 0.13 . Similarly, the rate of insulindependent diabetes was higher among patients in the minimal ventilation group with $2(6.5 \%)$ versus $2(3.7 \%)$ patients in the minimal and standard treatment groups, respectively, with a standardized difference of 0.13 . These minor imbalances were considered acceptable.

Due to unequal time points of postoperative $\mathrm{PaO}_{2} /$ $\mathrm{FiO}_{2}$ and arterial lactate level measurements among study patients, $\mathrm{PaO}_{2} / \mathrm{FiO}_{2}$ curves of the first 5 hours and arterial lactate curves of the first 15 postoperative hours were constructed for individual study patients. The areas under the curves standardized by the length of the follow-up were calculated to compare the two study groups. ${ }^{32}$

\section{Results}

The postoperative ventilation parameters, blood gas measurements, and complications are reported in Table 6. Patients in the minimal ventilation group had shorter total ventilation times than patients in the standard treatment group, 12.0 (IQR: 9.9-15.0) versus 14.0 (IQR: 12.0-16.3) hours, respectively $(\mathrm{p}=0.036)$. In addition, the arterial lactate levels were significantly lower in the MVV group, 0.99 (IQR: $0.81-1.39$ ) versus 1.28 (IQR: $0.99-1.86) \mathrm{mmol} / \mathrm{L}(\mathrm{p}=0.01)$. The postoperative 
Table 4. Demographic data after propensity score matching.

\begin{tabular}{|c|c|c|c|c|}
\hline Demographic data & $\begin{array}{l}\text { Minimal ventilation } \\
(n=3 I)\end{array}$ & $\begin{array}{l}\text { Standard treatment } \\
(n=54)\end{array}$ & $P$ value & $\begin{array}{l}\text { Standardized } \\
\text { difference }\end{array}$ \\
\hline Male $^{a}$ & $24(77.4)$ & $43(79.6)$ & 0.791 & 0.05 \\
\hline $\mathrm{Age}^{\mathrm{a}}$ (years) & $57.1(13.9)$ & $57.6(10.0)$ & 0.851 & 0.04 \\
\hline $\mathrm{BSA}^{\mathrm{a}}\left(\mathrm{m}^{2}\right)$ & $1.98(0.27)$ & $1.99(0.21)$ & 0.929 & 0.02 \\
\hline $\mathrm{GFR}^{\mathrm{a}}(\mathrm{mL} / \mathrm{min})$ & $92(64-118)$ & $89(80-116)$ & 0.596 & 0.02 \\
\hline Pulmonary hypertensiona & & & 0.998 & \\
\hline Normal & $18(58.1)$ & $3 \mid(57.4)$ & & 0.01 \\
\hline Moderate & $9(29.0)$ & $16(29.6)$ & & 0.01 \\
\hline Severe & $4(12.9)$ & $7(13.0)$ & & 0.00 \\
\hline Atrial fibrillation ${ }^{\mathrm{a}}$ & $13(41.9)$ & $22(40.7)$ & 1.000 & 0.02 \\
\hline Ejection fraction ${ }^{\mathrm{a}}$ & & & 1.000 & \\
\hline$>50 \%$ & $29(93.5)$ & $49(90.7)$ & & 0.10 \\
\hline$\leqslant 50 \%$ & $2(6.5)$ & $5(9.3)$ & & 0.10 \\
\hline NYHA ${ }^{a}$ & & & 0.944 & \\
\hline 1 & $6(19.4)$ & $10(18.5)$ & & 0.02 \\
\hline II & $16(51.6)$ & $30(55.6)$ & & 0.08 \\
\hline III & $7(22.6)$ & $12(22.2)$ & & 0.01 \\
\hline IV & $2(6.5)$ & $2(3.7)$ & & 0.13 \\
\hline Diabetes $^{\mathrm{a}}$ & & & 0.775 & \\
\hline No diabetes & $28(90.3)$ & $51(94.4)$ & & 0.16 \\
\hline Non-insulin dependent & $\mathrm{I}(3.2)$ & $\mathrm{I}(1.9)$ & & 0.09 \\
\hline Insulin dependent & $2(6.5)$ & $2(3.7)$ & & 0.13 \\
\hline Smokinga & & & 0.961 & \\
\hline No smoking & $25(80.6)$ & $44(79.6)$ & & 0.02 \\
\hline Ex-smoker & $4(12.9)$ & $8(14.8)$ & & 0.06 \\
\hline Current smoker & $2(6.5)$ & $3(5.6)$ & & 0.04 \\
\hline COPD & 0 & 0 & 1.000 & \\
\hline Asthma & $\mathrm{I}(3.2)$ & 0 & 0.365 & \\
\hline Hypertension & II (35.5) & $21(38.9)$ & 0.819 & \\
\hline Previous stroke & 0 & $\mathrm{I}(1.9)$ & 1.000 & \\
\hline TIA & $\mathrm{I}(3.2)$ & 0 & 1.000 & \\
\hline EuroSCORE I & $2.08(1.51-3.19)$ & $1.72(1.5 \mathrm{I}-2.14)$ & 0.255 & \\
\hline Degenerative mitral valve disease & $31(100)$ & $54(100)$ & 1.000 & \\
\hline Mitral valve leaflet pathology & & & 0.300 & \\
\hline Isolated posterior leaflet & $22(7 \mid .0)$ & $45(83.3)$ & & \\
\hline Isolated anterior leaflet & $4(12.9)$ & $4(7.4)$ & & \\
\hline Bileaflet & $5(16.1)$ & $4(7.4)$ & & \\
\hline
\end{tabular}

BSA: body surface area; GFR: glomerular filtration rate; NYHA: New York Heart Association; COPD: chronic obstructive pulmonary disease;

TIA: transient ischemic attack; EuroSCORE: European System for Cardiac Operative Risk Evaluation.

Data shown as number of patients (\%) or mean \pm SD (range) or median (interquartile range).

aVariables included in propensity score matching.

$\mathrm{PaO}_{2} / \mathrm{FiO}_{2}$ level, intensive care unit stay, and hospitalization length were similar in both groups.

There was no difference in the rate of postoperative infections between the two study groups. One patient in the standard ventilation group had catheter-related sepsis, and one patient in the minimal ventilation group had postoperative empyema. The rate of pneumonia was similar between the study groups $(3.2 \%$ and $1.9 \%$ patients in the minimal and standard treatment groups, respectively, $p=1.000$ ). The rate of postoperative non-infectious complications in both study groups was low. Two (6.5\%) patients in the minimal ventilation group and four patients $(7.4 \%)$ in the standard treatment group had UPE postoperatively $(\mathrm{p}=1.000)$. One patient in the minimal ventilation group had a transient ischemic attack postoperatively. There were no other significant complications among patients included in this study.

\section{Discussion}

In an attempt to reduce the risk of postoperative pulmonary dysfunction and postoperative UPE, 40 of 174 patients undergoing robotically assisted mitral valve 
Table 5. Operative data after propensity score matching.

\begin{tabular}{|c|c|c|c|c|}
\hline Operative data & $\begin{array}{l}\text { Minimal ventilation } \\
(n=3 I)\end{array}$ & $\begin{array}{l}\text { Standard treatment } \\
(n=54)\end{array}$ & $\mathrm{P}$ value & $\begin{array}{l}\text { Standardized } \\
\text { difference }\end{array}$ \\
\hline CPB time ${ }^{a}(\min )$ & $152(33)$ & $152(34)$ & 0.997 & 0.00 \\
\hline Cross-clamp time (min) & $104(28)$ & $105(26)$ & 0.860 & \\
\hline Console time (min) & |3| (33) & $132(33)$ & 0.942 & \\
\hline Operation length (min) & $251(40)$ & $245(4 I)$ & 0.588 & \\
\hline \multicolumn{5}{|l|}{ Concomitant surgery } \\
\hline TVP & I (3.2) & $3(5.6)$ & 1.000 & \\
\hline AF ablation & $9(29.0)$ & $12(22.2)$ & 0.602 & \\
\hline Myxoma resection & 0 & 0 & 1.000 & \\
\hline Mitral valve repair & $31(100)$ & $54(100)$ & & \\
\hline Isolated neochord implantation & $17(54.8)$ & $23(42.6)$ & 0.367 & \\
\hline Isolated leaflet resection & $7(22.6)$ & $20(37.0)$ & 0.228 & \\
\hline Neochord + resection & $5(16.1)$ & $3(5.6)$ & 0.134 & \\
\hline Commissuroplasty or cleft closure & $2(6.5)$ & $5(9.3)$ & 1.000 & \\
\hline Isolated annuloplasty & 0 & $2(3.7)$ & 0.531 & \\
\hline
\end{tabular}

CPB: cardiopulmonary bypass; TVP: tricuspid valve repair; AF: atrial fibrillation.

Data shown as number of patients (\%) or mean \pm SD (range) or median (interquartile range).

a $V$ ariables included in propensity score matching.

Table 6. Outcomes and complications.

\begin{tabular}{|c|c|c|c|}
\hline & Minimal ventilation $(n=31)$ & Standard treatment $(n=54)$ & $P$ value \\
\hline \multicolumn{4}{|l|}{ Outcomes } \\
\hline Total ventilation time (hours) & $12.0(9.9-15.0)$ & $14.0(12.0-16.3)$ & 0.036 \\
\hline ICU stay (days) & $1.0(1.0-1.0)$ & $1.0(1.0-1.0)$ & 0.460 \\
\hline Hospitalization time (days) & $7(6-8)$ & $7(6-8)$ & 0.774 \\
\hline Postoperative $\mathrm{PaO}_{2} / \mathrm{FiO}_{2}(\mathrm{mmHg})$ & $314(94)$ & $312(107)$ & 0.912 \\
\hline Postoperative arterial lactate (mmol/L) & $0.99(0.81-1.39)$ & $1.28(0.99-1.86)$ & 0.010 \\
\hline \multicolumn{4}{|l|}{ Complications } \\
\hline 30-day mortality & 0 & 0 & 1.000 \\
\hline Unilateral pulmonary edema & $2(6.5)$ & $4(7.4)$ & 1.000 \\
\hline TIA & $\mathrm{I}(3.2)$ & 0 & 0.365 \\
\hline Dialysis & 0 & 0 & 1.000 \\
\hline Myocardial infarction & 0 & 0 & 1.000 \\
\hline Stroke & 0 & 0 & 1.000 \\
\hline Second pump run & I (3.2) & I (I.9) & 1.000 \\
\hline Pacemaker implantation & $\mathrm{I}(3.2)$ & I (1.9) & 1.000 \\
\hline Low output syndrome or ECMO & 0 & 0 & 1.000 \\
\hline IABP & 0 & 0 & 1.000 \\
\hline Sepsis & 0 & $\mathrm{I}(\mathrm{I.9})$ & 1.000 \\
\hline Pneumonia & I (3.2) & I (I.9) & 1.000 \\
\hline Empyema & I (3.2) & 0 & 0.365 \\
\hline Wound infection & 0 & 0 & 1.000 \\
\hline
\end{tabular}

ICU: intensive care unit; $\mathrm{PaO}_{2}$ : arterial partial pressure of oxygen; $\mathrm{FiO}_{2}$ : fraction of inspired oxygen; TIA: transient ischemic attack; ECMO: extracorporeal membrane oxygenation; IABP: intra-aortic balloon pump.

Data shown as number of patients $(\%)$ or mean \pm SD (range) or median (interquartile range).

surgery were ventilated with a small tidal volume during $\mathrm{CPB}$. In our standard practice, patients are disconnected from the ventilator during CPB. The effect of MVV on postoperative ventilation-related parameters and morbidity was assessed in this study. Patients who were ventilated using MVV had shorter ventilation times in comparison to patients who were not ventilated during $\mathrm{CPB}$. In addition, postoperative lactate levels were lower among patients in the minimal ventilation group, suggesting better perfusion of the lungs during surgery. ${ }^{19,21}$ The minimal ventilation method did not have any effect on postoperative $\mathrm{PaO}_{2} / \mathrm{FiO}_{2}$ levels, intensive care unit 
stay, or hospitalization length. Two (6.5\%) patients in the minimal ventilation group and four $(7.4 \%)$ patients in the standard ventilation group developed UPE, and this difference was not statistically significant.

In thoracic surgery, the use of CPAP or HFJV to the collapsed lung during OLV has been evaluated with improved oxygenation, reduced pulmonary shunting, and lower local inflammatory response of the affected lung. ${ }^{24-28}$ In studies assessing HFJV during OLV, HFJV has improved respiratory parameters even though tidal volumes generated by HFJV are smaller than the anatomic dead space. ${ }^{27,28,33}$ In cardiac surgery with the sternotomy approach, the effects of CPAP and mechanical ventilation during $\mathrm{CPB}$ on postoperative oxygenation and pulmonary dysfunction have been varying, with some results suggesting that CPAP may improve postoperative oxygenation without any effect on clinical outcomes. ${ }^{22,23}$ In our series of minimally invasive and robotically assisted mitral valve operations, the use of CPAP or PEEP to the collapsed lung was not considered feasible due to the resulting limited visibility to the operative field. Instead, both lungs were ventilated without PEEP and with a tidal volume of $50-80 \mathrm{~mL}$, which did not affect the surgical exposure of the heart. In contrast to the studies evaluating the effect of different ventilation methods on respiratory parameters during OLV, the operations in our series were performed using $\mathrm{CPB}$, and therefore, the impact of MVV on intraoperative oxygenation was not evaluated. The aim of MVV was to reduce intraoperative lung hypoperfusion and subsequently reduce postoperative pulmonary dysfunction. Small tidal volumes were hypothesized to recruit alveoli and reduce hypoxic pulmonary vasoconstriction to allow blood flow to otherwise hypoperfused lung parenchyma during $\mathrm{CPB}$. The lower postoperative lactate levels among MVV patients support this hypothesis.

This is a retrospective study with a relatively small number of study patients. Even though PSM resulted in two well-matched study groups of patients with either minimal ventilation or standard treatment, the effect of selection bias cannot be fully eliminated. The decision to use the minimal ventilation strategy for an individual patient was based on anesthesiologist preference and was not driven by patient characteristics. Patients were therefore not selected for minimal ventilation. After PSM, patients with NYHA IV heart failure symptoms and patients with insulin-dependent diabetes were slightly more common in the minimal ventilation group with respect to the standardized differences between the groups. This difference might favor the standard treatment group and reduce the observed positive effects in the minimal ventilation group.

The main result of this study is that ventilation time was shorter among patients who were ventilated using the minimal ventilation method. In our practice, the extubation criteria of patients operated using robotic assistance have been the same during the whole robotic surgical program from 2011 to 2017. Despite the clear institutional extubation criteria, the final decision of when a patient is extubated is subjective and specialist dependent. However, intensive care personnel were not aware of the ventilation method used during $\mathrm{CPB}$, and therefore, the impact of these confounding factors is assumed to be minimal. There may also be unrecognized factors that have an impact on the reported results.

To our knowledge, this is the first study that evaluates the effect of MVV on postoperative oxygenation and clinical recovery after robotically assisted mitral valve surgery. Postoperative lactate levels were lower among patients in the MVV group, suggesting better lung perfusion during surgery. ${ }^{19,21}$ In addition, total ventilation times were shorter among patients in the MVV group, but the differences were in fact small, and further studies are required to confirm the possible advantages of the MVV method in robotically assisted cardiac surgery.

\section{Declaration of Conflicting Interests}

The author(s) declared the following potential conflicts of interest with respect to the research, authorship, and/or publication of this article: A.V. is Proctor of Intuitive Surgical 2014. The remaining authors do not have any conflicts of interest to disclose.

\section{Funding}

The author(s) disclosed receipt of the following financial support for the research, authorship, and/or publication of this article: The study was supported by grants from the Finnish Society of Angiology and Finnish state funding for the Helsinki University Central Hospital regional expert responsibility.

\section{ORCID iDs}

Risto Kesävuori (iD https://orcid.org/0000-0002-1020-0271 Janne J Jokinen iD https://orcid.org/0000-0002-1875-5933

\section{References}

1. Cao C, Wolfenden $\mathrm{H}$, Liou $\mathrm{K}$, et al. A meta-analysis of robotic vs. conventional mitral valve surgery. Ann Cardiothorac Surg 2015; 4: 305-314.

2. Mihaljevic T, Jarrett CM, Gillinov AM, et al. Robotic repair of posterior mitral valve prolapse versus conventional approaches: potential realized. J Thorac Cardiovasc Surg 2011; 141: 72-80.e1-e4.

3. Murphy DA, Moss E, Binongo J, et al. The expanding role of endoscopic robotics in mitral valve surgery: 1,257 consecutive procedures. Ann Thorac Surg 2015; 100: 1675-1681.

4. Nifong LW, Rodriguez E, Chitwood WR Jr. 540 consecutive robotic mitral valve repairs including concomitant atrial fibrillation cryoablation. Ann Thorac Surg 2012; 94: 38-42.

5. Suri RM, Burkhart HM, Daly RC, et al. Robotic mitral valve repair for all prolapse subsets using techniques 
identical to open valvuloplasty: establishing the benchmark against which percutaneous interventions should be judged. J Thorac Cardiovasc Surg 2011; 142: 970-979.

6. Suri RM, Dearani JA, Mihaljevic T, et al. Mitral valve repair using robotic technology: Safe, effective, and durable. J Thorac Cardiovasc Surg 2016; 151: 1450-1454.

7. Suri RM, Taggarse A, Burkhart HM, et al. Robotic mitral valve repair for simple and complex degenerative disease: midterm clinical and echocardiographic quality outcomes. Circulation 2015; 132: 1961-1968.

8. Yoo JS, Kim JB, Jung SH, et al. Mitral durability after robotic mitral valve repair: analysis of 200 consecutive mitral regurgitation repairs. J Thorac Cardiovasc Surg; 2014; 148: 2773-2779.

9. Moss E, Halkos ME, Binongo JN, et al. Prevention of unilateral pulmonary edema complicating robotic mitral valve operations. Ann Thorac Surg 2017; 103: 98-104.

10. Irisawa $Y$, Hiraoka A, Totsugawa $\mathrm{T}$, et al. Re-expansion pulmonary oedema after minimally invasive cardiac surgery with right mini-thoracotomy. Eur J Cardiothorac Surg 2016; 49: 500-505.

11. Fujita N, Miyasaka K, Okada O, et al. Localized pulmonary edema in the middle and inferior lobes of the right lung after one-lung ventilation for minimally invasive mitral valve surgery. J Cardiothorac Vasc Anesth 2015; 29: 1009-1012.

12. Kitahara H, Okamoto K, Kudo M, et al. Successful management of severe unilateral re-expansion pulmonary edema after mitral valve repair with mini-thoracotomy using extracorporeal membrane oxygenation. Gen Thorac Cardiovasc Surg 2017; 65: 164-166.

13. Tutschka MP, Bainbridge D, Chu MW, et al. Unilateral postoperative pulmonary edema after minimally invasive cardiac surgical procedures: a case-control study. Ann Thorac Surg 2015; 99: 115-122.

14. Keyl C, Staier K, Pingpoh C, et al. Unilateral pulmonary oedema after minimally invasive cardiac surgery via right anterolateral minithoracotomy. Eur J Cardiothorac Surg 2015; 47: 1097-1102.

15. Madershahian N, Wippermann J, Sindhu D, et al. Unilateral re-expansion pulmonary edema: a rare complication following one-lung ventilation for minimal invasive mitral valve reconstruction. J Card Surg 2009; 24: 693-694.

16. Kottenberg-Assenmacher E, Kamler M, Peters J. Minimally invasive endoscopic port-access intracardiac surgery with one lung ventilation: impact on gas exchange and anaesthesia resources. Anaesthesia 2007; 62: 231-238.

17. Naik R, George G, Karuppiah S, et al. Hyperlactatemia in patients undergoing adult cardiac surgery under cardiopulmonary bypass: causative factors and its effect on surgical outcome. Ann Card Anaesth 2016; 19: 668-675.

18. Ranucci $M$, De Toffol $B$, Isgro $G$, et al. Hyperlactatemia during cardiopulmonary bypass: determinants and impact on postoperative outcome. Crit Care 2006; 10: R167.
19. Gasparovic H, Plestina S, Sutlic Z, et al. Pulmonary lactate release following cardiopulmonary bypass. Eur $J$ Cardiothorac Surg 2007; 32: 882-887.

20. Demers P, Elkouri S, Martineau R, et al. Outcome with high blood lactate levels during cardiopulmonary bypass in adult cardiac operation. Ann Thorac Surg 2000; 70: 2082-2086.

21. Bendjelid K, Treggiari MM, Romand JA. Transpulmonary lactate gradient after hypothermic cardiopulmonary bypass. Intensive Care Med 2004; 30: 817-821.

22. Schreiber JU, Lance MD, de Korte M, et al. The effect of different lung-protective strategies in patients during cardiopulmonary bypass: a meta-analysis and semiquantitative review of randomized trials. J Cardiothorac Vasc Anesth 2012; 26: 448-454.

23. Wang YC, Huang $\mathrm{CH}, \mathrm{Tu} \mathrm{YK}$. Effects of positive airway pressure and mechanical ventilation of the lungs during cardiopulmonary bypass on pulmonary adverse events after cardiac surgery: a systematic review and meta-analysis. J Cardiothorac Vasc Anesth 2018; 32: 748-759.

24. Verhage RJ, Boone J, Rijkers GT, et al. Reduced local immune response with continuous positive airway pressure during one-lung ventilation for oesophagectomy. $\mathrm{Br}$ J Anaesth 2014; 112: 920-928.

25. Hogue CW Jr. Effectiveness of low levels of nonventilated lung continuous positive airway pressure in improving arterial oxygenation during one-lung ventilation. Anesth Analg 1994; 79: 364-367.

26. Dikmen Y, Aykac B, Erolcay H. Unilateral high frequency jet ventilation during one-lung ventilation. Eur J Anaesthesiol 1997; 14: 239-243.

27. Abe K, Oka J, Takahashi H, et al. Effect of high-frequency jet ventilation on oxygenation during one-lung ventilation in patients undergoing thoracic aneurysm surgery. $J$ Anesth 2006; 20: 1-5.

28. Godet G, Bertrand M, Rouby JJ, et al. High-frequency jet ventilation vs continuous positive airway pressure for differential lung ventilation in patients undergoing resection of thoracoabdominal aortic aneurysm. Acta Anaesthesiol Scand 1994; 38: 562-568.

29. Rehfeldt KH, Andre JV, Ritter MJ. Anesthetic considerations in robotic mitral valve surgery. Ann Cardiothorac Surg 2017; 6: 47-53.

30. Bernstein WK, Walker A. Anesthetic issues for robotic cardiac surgery. Ann Card Anaesth 2015; 18: 58-68.

31. Kesavuori R, Raivio P, Jokinen JJ, et al. Early experience with robotic mitral valve repair with intra-aortic occlusion. J Thorac Cardiovasc Surg 2018; 155: 1463-1471.

32. Matthews JN, Altman DG, Campbell MJ, et al. Analysis of serial measurements in medical research. BMJ 1990; 300: 230-235.

33. Krishnan JA, Brower RG. High-frequency ventilation for acute lung injury and ARDS. Chest 2000; 118: 795-807. 